\title{
Comparison of Saccharina japonica-Undaria pinnatifida Mixture and Minoxidil on Hair Growth Promoting Effect in Mice
}

\author{
Ki Soo Park, Dae Hwan Park \\ Department of Plastic and Reconstructive Surgery, Daegu Catholic University Medical Center, Catholic University of Daegu School of \\ Medicine, Daegu, Korea
}

Background Algae have traditionally been used for promotion of hair growth. Use of hair regrowth drugs, such as minoxidil, is limited due to side effects. The aim of this study was to examine a mixture of Saccharina japonica and Undaria pinnatifida (L-U mixture) on hair growth and to compare the promoting effect of hair growth by a $3 \%$ minoxidil and a L-U mixture.

Methods To evaluate the hair growth-promoting activity, saline, 50\% ethanol, 3\% minoxidil, and the L-U mixture were applied 2 times a day for a total of 14 days on the dorsal skin of C57BL/6 mice after depilation. Analysis was determined by using a high-resolution hair analysis system, real-time polymerase chain reaction, and H\&E staining.

Results On day 14, the hair growth effect of the L-U mixture was the same as that of the $3 \%$ minoxidil treatment. The $\mathrm{L}-\mathrm{U}$ mixture significantly $(\mathrm{P}<0.05)$ stimulated hair growth-promoting genes, as vascular endothelial growth factor (VEGF) and insulin-like growth factor -1. Increase of VEGF was observed in the L-U mixture group compared with minoxidil and the negative control. In contrast, the L-U mixture suppressed the expression of transforming growth factor- $\beta 1$, which is the hair loss-related gene. In histological examination in the L-U mixture and minoxidil groups, the induction of an anagen stage of hair follicles was faster than that of control groups.

Conclusions This study provides evidence that the L-U mixture can promote hair growth in mice, similar to the effect from minoxidil, and suggests that there is potential application for hair loss treatments.

Keywords Alopecia / Saccharina Japonica / Undaria pinnatifida / Minoxidil
Correspondence: Dae Hwan Park Department of Plastic and Reconstructive Surgery, Daegu Catholic University Medical Center, Catholic University of Daegu School of Medicine, 33 Duryugongwon-ro 17-gil, Nam-gu, Daegu 42472, Korea Tel: +82-53-650-4581 Fax: +82-53-650-4584 E-mail:dhpark@cu.ac.kr
This research was supported by the Basic Science Research Program through the National Research Foundation of Korea (NRF) funded by the Ministry of Education, Science and Technology (2012R1A1A2009247).

L-U mixture (the extract of Laminaria japonica-Undaria pinnatifida) was supported by JW Bio Co. (Daegu, Korea).

No potential conflict of interest relevant to this article was reported.

\section{INTRODUCTION}

The use of Food and Drug Adminstration (FDA) approved hair regrowth drugs such as finasteride (Propecia, Merck Sharp \& Dohme Corp., Rahway, NJ, USA) and minoxidil (Rogain, Phar- macia and Upjohn, Kalamazoo, MI, USA), is limited and transient due to side effects such as irregular heartbeat or weight gain [1-3]. Hair growth is a complex interaction mechanism between epithelial cells and dermal cells of hair follicles. The hair follicle is remodeled during cyclical periods of growth (anagen), 
regression (catagen), and rest (talogen) [4,5]. The dermal papilla cell, epithelial cell, and enclosed hair follicle each release growth factors or inhibition factors during a cycle of hair growth state or degeneration state. Basic fibroblast growth factor (bFGF), insulin-like growth factor-1 (IGF-1), keratinocyte growth factor, and vascular endothelia growth factor (VEGF) are well-studied hair growth factors. The epithelial growth factor (EGF) and transforming growth factor- $\beta$ (TGF- $\beta$ ) are inhibition factors [6,7].

Companies are developing hair growth materials and hair growth drugs using natural resources. Algae have traditionally been used for promotion of hair growth. Studies have focused on understanding the relationship between hair growth and algae for potential therapeutic applications. For example, anagen progression of the hair shaft was induced after topical application of Ishige sinicola extract on the back of mice, [8]. Grateloupia elliptica, the red algae, has been reported to prevent hair loss in vitro [9]. The brown algae, Ecklonia cava contains dioxinodehydroeckol, which promotes hair growth through the stimulation of dermal papilla cells and outer root sheath cells [10]. Laminaria japonica and Undaria pinnatifida, also brown algae, have significant anti-inflammatory activities without serious toxic effects at moderate doses. These anti-inflammatory activities are related to treatment of hair loss, because scalp inflammation is one of the causes of hair loss [11]. Single taxon studies about the effects of algal treatment on hair growth have been published, but the hair growth effect of a single algal taxon does not yet surpass the therapeutic effect of minoxidil.

We investigated the hair-growth effect on C57BL/6 mice using a combined mixture of the brown algae $L$. japonica and $U$. pinnatifida. If $\mathrm{L}-\mathrm{U}$ mixture increases hair regrowth more than existing hair growth solution or single-alga extract, this study can have a positive impact on future hair-growth solution development.

\section{METHODS}

\section{Materials}

L-U mixture (the extract of L. japonica and U. pinnatifida) was supplied by JW Bio Co. (Daegu, Korea), and 3\% minoxidil was purchased from Nanopharm Corp. (Seoul, Korea) Saline and $50 \% \mathrm{EtOH}$ are used for respectively negative control and solvent control.

\section{Experiment animals}

Five-week-old male C57BL/ 6 mice with black hair were used in this experiment. In the animal laboratory, temperatures were maintained at $23^{\circ} \mathrm{C} \pm 3^{\circ} \mathrm{C}$, relative humidity was maintained at
$50 \% \pm 10 \%$, and day and night lengths were each maintained for a period of 12 hours. Mice were reared in isolation in mice breeding cages and allowed free access to food. The mice were divided into four groups (normal saline treated group, $50 \%$ ethanol treated group, 3\% minoxidil treated group, L-U mixture treated group), and each group consisted of four mice (a total of 16 mice). Hair growth solution was applied topically to the shaved skin area; sample solutions $(150 \mu \mathrm{L})$ were applied daily for a total of 14 days. All experimental protocols were conducted in accordance with guidelines for care and use of laboratory animals approved by the Institutional Animal Care and Use Committee of Korea (2012-0216-CU-AEC-01-Y).

\section{Gross confirmatory experiment based on hair regrowth scoring system}

The depilatory Niclean (Ildong Pharmaceutical Co., Ltd., Seoul, Korea) was applied on the back of mice. And hair was shaved Treatments consisted of $150 \mu \mathrm{L}$ of each sample (normal saline, negative control; $50 \%$ ethanol, solvent control; $3 \%$ minoxidil, positive control; L-U extract) applied to the depilated area of each mouse 2 times a day for 14 days. Conditions of hair growth were examined macroscopically on days $1,4,7,10$, and 14 of the experiment. Mice were photographed after being lightly anesthetized with Zoletil (Virbac, Carros, France) and Rompun (Bayer, Seoul, Korea), mixed in the ratio of 8:2 and diluted 10fold with normal saline, followed by intraperitoneal injection of $10 \mu \mathrm{L} / 10 \mathrm{~g}$. Photos were taken to check hair growth, and hair growth state was scored as $0(0 \%), 1(1 \%-19 \%), 2(20 \%-39 \%)$, $3(40 \%-59 \%), 4(60 \%-79 \%)$, and $5(80 \%-100 \%)$.

\section{Hair analysis using a high-resolution hair analysis system}

A high resolution hair analysis system (Professional Scientific Instrument Co., Ltd., Yongin, Korea) was used for the analysis of hair. Hair analysis was performed on days 1, 4, 7, 10, and 14 of the experiment and measured the density of hair, hair follicle lengths, and hair thicknesses of the treated areas of the six mice in each of the four groups. Hair densities were measured by counting the number of hairs per $0.4 \mathrm{~mm}^{2}$, and hair follicle lengths and hair thicknesses were measured from 20 hairs collected from the treated area of each mouse using pincers. Measured values were averaged by treatment group for each day (i.e., $1,4,7,10$, and 14 days) for analysis.

\section{Histological analysis}

On day 14 of the experiment, following anesthetization, the skin in the treated areas where samples were applied were surgically removed using a no. 15 scalpel blade, fixed immediately using 
$10 \%$ formalin, dehydrated using alcohol and xylene, embedded in paraffin, and sectioned into width of $5 \mu \mathrm{m}$, followed by removal of paraffin using alcohol and xylene. Slices were stained with hematoxylin and eosin ( $\mathrm{H} \& \mathrm{E})$, followed by observation using a light microscope. Sixteen tissue samples were used for staining (taken from 4 mice in the 4 groups, for a total of 16 mice).

\section{Real-time polymerase chain reaction analysis}

Real-time polymerase chain reaction (RT-PCR) was used to analyze the expression of mRNA for IGF-1, transforming growth factor TGF- $\beta 1$, and glyceraldehyde-3-phosphate dehydrogenase (internal control). Skin was taken from each mouse in four groups (a total of 16 mice) for RT-PCR and histological samples for the same time. Real-time PCR was performed three times per skin sample. Total RNA was extracted from skin samples with TRIzol reagent (Takara Bio Inc., Kusatsu, Japan) and RTPCR was performed using an oligo(dT) RT premix kit (iNtRON Biotechnology, Daejeon, Korea). Real-time PCR was performed with a MJ Mini Thermal Cycler real time system (Bio-Rad, Hercules, CA, USA) using SYBR Premix Ex Taq (Takara Bio Inc.). The thermal cycle reaction was performed at $95^{\circ} \mathrm{C}$ for 30 seconds, followed by 40 cycles of $95^{\circ} \mathrm{C}$ for $5 \mathrm{sec}-$ onds and $60^{\circ} \mathrm{C}$ for 30 seconds. The dissociation stage was initiated at $95^{\circ} \mathrm{C}$ for 15 seconds, followed by 1 cycle of $60^{\circ} \mathrm{C}$ for 30 seconds and $95^{\circ} \mathrm{C}$ for 15 seconds.

\section{Gas chromatography and mass spectrometry analysis}

Extract concentrate $(8.4 \mathrm{~g})$ from the L-U mixture was obtained by vacuum evaporation method and dissolved in $200 \mathrm{~mL} \mathrm{H}_{2} \mathrm{O}$. And then $200 \mathrm{~mL}$ methylene chloride $\left(\mathrm{CH}_{2} \mathrm{Cl}_{2}\right)$ was added to this aqueous solution, which was then left to separate the $\mathrm{CH}_{2} \mathrm{Cl}_{2}$ layer and water layer (separation performed 3 times). The yield $(0.2182 \mathrm{~g})$ was collected by vacuum evaporation. The partite $\mathrm{CH}_{2} \mathrm{Cl}_{2}$ solvent was extracted from the $\mathrm{L}-\mathrm{U}$ mixture, and gas chromatography with mass spectrometry (GC-MS) was used for analysis. The gas chromatography system (GC; Agilent Technologies, PA, USA) analysis was done using a DB-5 capillary column (J\&W Science Inc., Folsom, CA, USA), $30 \mathrm{~m}$ length $\times 0.25 \mathrm{~mm}$ id $\times 0.25 \mu \mathrm{m}$ film. Helium was used as the carrier gas at a flow rate of $1 \mathrm{~mL} / \mathrm{min}$. The injection and detector temperatures were $280^{\circ} \mathrm{C}$, and the oven temperature was programmed initial $40^{\circ} \mathrm{C}$ for 2 minutes, raised to $250^{\circ} \mathrm{C}$ at a rate of $10^{\circ} \mathrm{C} / \mathrm{min}$, and held at that temperature for 10 minutes. MS (JEOL GC MateII mass spectrometer, JEOL Ltd., Tokyo, Japan) analysis was done under electron impact ionization at 70 $\mathrm{eV}$ of electron energy with a range from 10 to 500 at a rate of 1 $\mathrm{scan} / \mathrm{sec}$. Ion source temperature was $250^{\circ} \mathrm{C}$. The chemical structure of each constituent was identified by searching and comparing mass data with the National Institute of Standards and Technology research library.

\section{Statistical analysis}

All statistical analyses were performed using the SPSS software package for Windows ver. 18.0 (SPSS Inc., Chicago, IL, USA). The Kruskal-Wallis test was used as the nonparametric method to compare each score by group. Multiple comparison was performed by the Dunn procedure. All data were presented by boxplot with median, first quartile, third quartile, upper fence, and lower fence. Statistical significance level was set at $\mathrm{P}<0.05$ and all data analysis was performed by a medical statistician.

\section{RESULTS}

\section{Effect of L-U mixture on hair regrowth}

The saline, 50\% ethanol, L-U mixture, and 3\% minoxidil were administered to C57BL/6 mice for two weeks (14 days) after depilation. Pink-colored skin was observed on day 4 of the experiment in all groups. But on day 7 of the experiment, in the L-U mixture group and 3\% minoxidil group, a light-black skin color began to appear. On day 10, hair density was greater compared to the normal saline and 50\% ethanol groups (Fig. 1B). On day 14, the depilated areas were almost covered with fullygrown hair in the L-U mixture group (Fig. 1A). Hair growth scores of the L-U mixture and 3\% minoxidil groups were significantly higher compared with the normal saline group (L-U mixture, $\mathrm{P}=0.008 ; 3 \%$ minoxidil, $\mathrm{P}=0.034$ ) (Fig. $1 \mathrm{C}$ ).

\section{Results of hair analysis performed using a high- resolution hair analysis system}

On day 14 of the experiment, hair width and length of follicle were measured in all groups using a hair analysis system. Increase in hair width was observed in the L-U mixture and 3\% minoxidil groups, compared to the normal saline and 50\% ethanol groups (Fig. 2A). The width of follicles on day 14 in the L-U mixture group was significantly increased, compared to the normal saline group $(\mathrm{P}=0.020)$ (Fig. $2 \mathrm{~B})$. The length of follicles on day 14 was increased in the L-U mixture and 3\% minoxidil groups, compared to the normal saline and 50\% ethanol groups. The length of the follicles of the L-U mixture group were similar to those of the $3 \%$ minoxidil group, although not significantly $(\mathrm{P}=0.53)$ (Fig. 2C).

\section{Histological characteristics}

Staining with H\&E showed that the roots of hair follicles of the control groups (negative control: saline, solvent control: $50 \%$ 


\section{Fig. 1. Time dependent changes of hair regrowth}

C57BL/6 mice were treated with normal saline, 50\% ethanol, the extract of Laminaria japonica and Undaria pinnatifida (L-U mixture), and 3\% minoxidil for a period of 2 weeks. Photometric observation after $1,4,7,10$, and 14 days (A) and comparison of hair density using a high resolution hair analysis system $(\times 300)$ after topical application of normal saline, $50 \%$ ethanol, L-U mixture and 3\% minoxidil at 10 and 14 days (B). (C) Hair growth was evaluated by the scoring index: $0(0 \%), 1$ (1\%-19\%), 2 (20\%-39\%), 3 (40\%-59\%), 4 $(60 \%-79 \%)$, and $5(80 \%-100 \%)$. The Kruskal-Wallis test was used to compare the value of hair growth score. The result was statistically significant $(P=0.007)$. The multiple comparison was performed by Dunn procedure. ${ }^{a} \mathrm{P}$-value, significantly different than the normal saline group; b) $P$-value, significantly different than the $50 \%$ EtOH group.

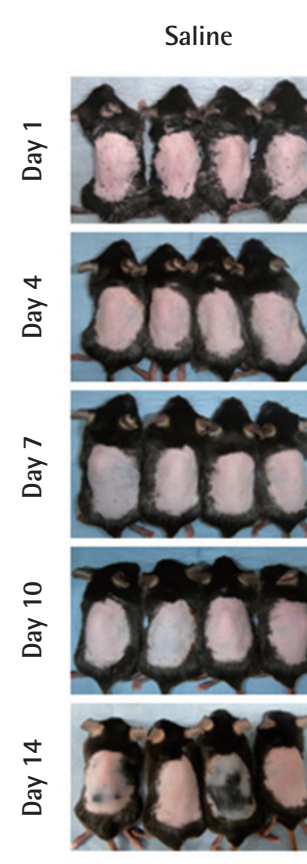

Saline
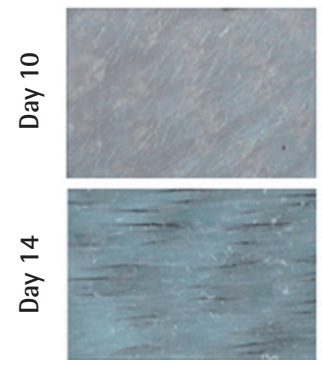
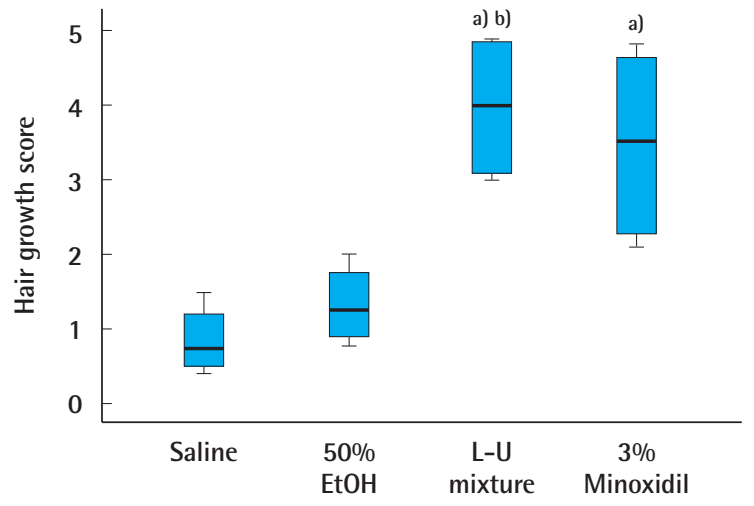

\begin{tabular}{c|c|c|c}
\hline P-value & $50 \%$ EtOH & L-U mixture & $3 \%$ Minoxidil \\
\hline Saline & 0.440 & $0.008^{\mathrm{a})}$ & $0.034^{\mathrm{a})}$ \\
\hline $50 \%$ EtOH & - & $0.041^{\mathrm{b})}$ & 0.107 \\
\hline L-U mixture & - & - & 0.301 \\
\hline
\end{tabular}

ethanol) remained mostly small and round, while the roots of hair follicles treated with the L-U mixture and 3\% minoxidil showed more growth. The numbers of basal cells of the hair root of the L-U mixture and 3\% minoxidil treated groups increased compared to the control groups; in addition, hair follicles treated with L-U mixture and 3\% minoxidil displayed large hair bulbs and well-differentiated hair shafts. In contrast, only a few well-formed hair follicles were found in the groups treated with saline and 50\% ethanol (Fig. 3).

\section{Molecular biological analysis}

Groups treated with the L-U mixture and 3\% minoxidil showed significantly increased gene expression of IGF-1, compared to the control groups $(\mathrm{P}<0.05)$. The $3 \%$ minoxidil group showed 


\section{Fig. 2. Comparison of hair follicle width and length}

(A) Picture of collected hair follicles $(\times 300)$. (B) Analysis of hair follicles, measured at the greatest width. The Kruskal-Wallis test was used to compare the value of hair growth score. The result was statistically significant $(P=0.040)$. The multiple comparison was performed by the Dunn procedure. (C) Analysis of hair follicles, measured at the greatest length. L-U mixture, the extract of Laminaria japonica and Undaria pinnatifida. a) P-value, significantly different than the normal saline group.
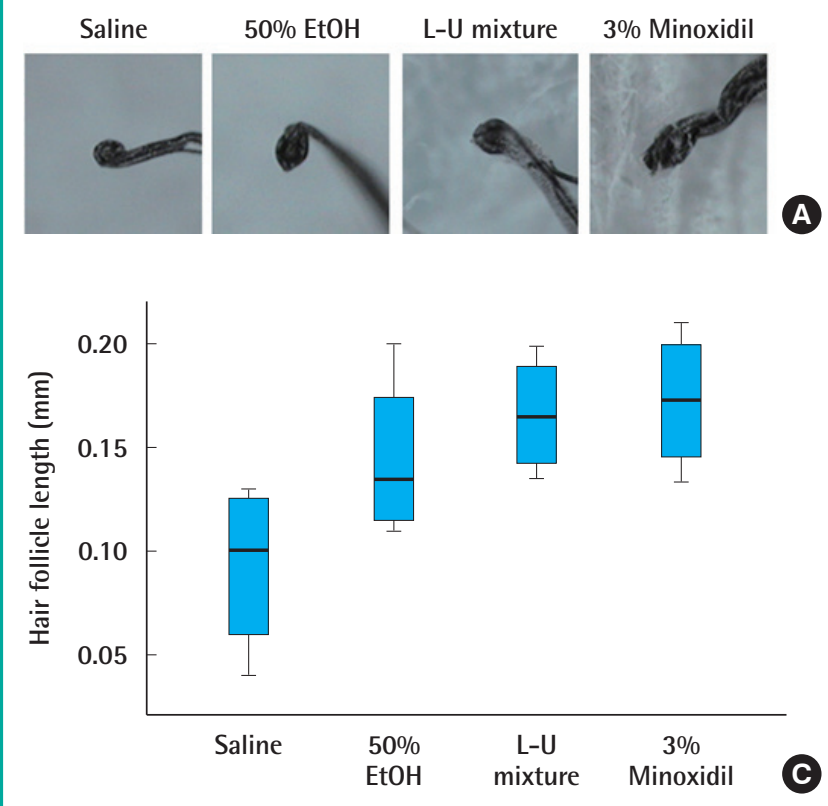

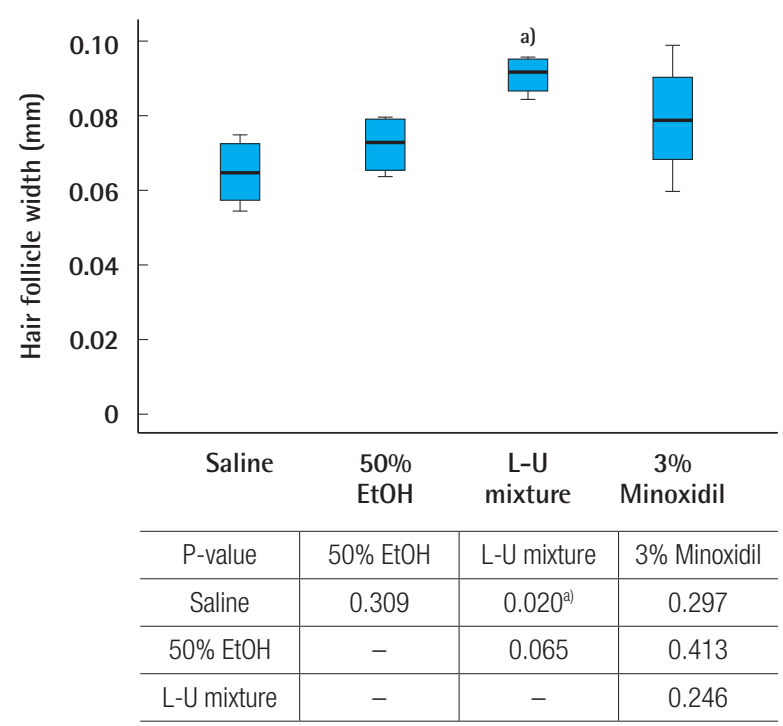

\section{Fig. 3. Histological analysis $(\times 100)$}

Histological observed treated skin of C57BL/6 mice with hematoxylin and eosin (H\&E) staining. Compounds (150 $\mu \mathrm{L}$ ) were applied to skin of mice for 2 weeks. (A) Normal saline. (B) 50\% Ethanol group. (C) The extract of Laminaria japonica and Undaria pinnatifida (L-U mixture). (D) 3\% Minoxidil.
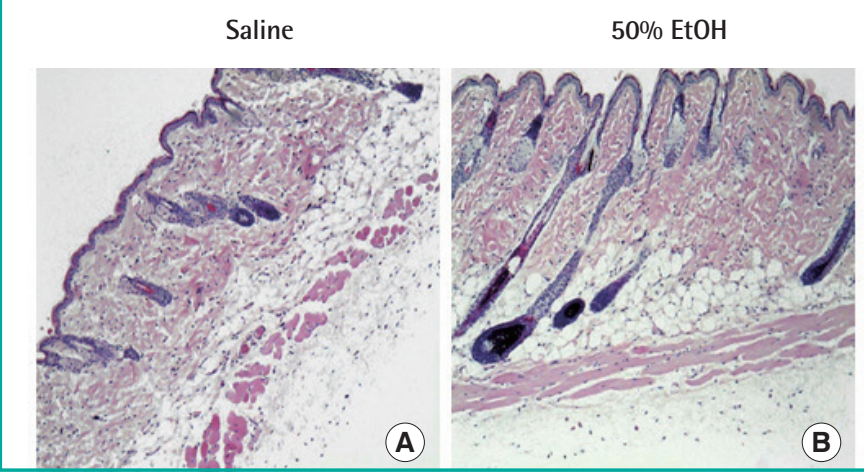

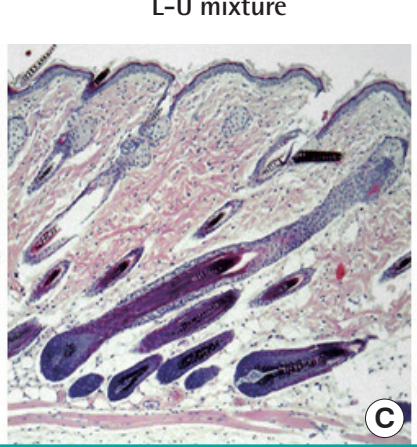

c)

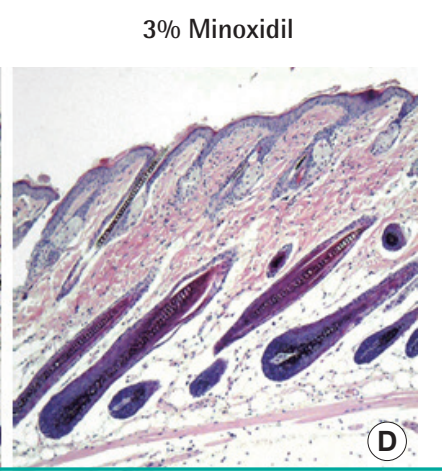

a greater increase of gene expression of IGF-1 than that of the L-U mixture treated group (Fig. 4A). Decreased gene expression of TGF- $\beta 1$ was observed in the group treated with $\mathrm{L}-\mathrm{U}$ mixture, compared to the normal saline group (Fig. 4B). L-U mixture and 3\% minoxidil treated groups showed increased gene expression of VEGF compared to the normal saline group (Fig. 4C).

\section{GC-MS analysis}

The $\mathrm{CH}_{2} \mathrm{Cl}_{2}$ fraction had 18 components. Nonacosan-10-ol and $\beta$-sitosterol were major components; (-)-loliolide was the third component and has been identified in marine algae (red, brown, and green algae) and also in U. pinnatifida (Table 1).

\section{DISCUSSION}

Treatment of hair loss can be divided into two groups: surgical treatments, such as hair implants, and medical treatments, such as the FDA approved drugs minoxidil and finasteride [3]. Although surgical treatment guarantees optimal improvement 


\section{Fig. 4. Analysis of gene expression by real time polymerase chain reaction}

(A) Insulin like growth factor type 1 (IGF-1) mRNA expression. (B) Transforming growth factor (TGF- $\beta 1$ ) mRNA expression. (C) Vascular endothelial growth factor (VEGF) mRNA expression. Glyceraldehyde-3-phosphate dehydrogenase was used as a comparative control. The Kruskal-Wallis test was used to compare the value of hair growth score. The result was statistically significant $(A, P=0.007 ; B$, $P=0.008 ; C, P=0.009)$. The multiple comparison was performed by Dunn procedure. ${ }^{\text {al)}} \mathrm{P}$-value, significantly different than the normal saline group; ${ }^{b} \mathrm{P}$-value, significantly different than the $50 \% \mathrm{EtOH}$ group.

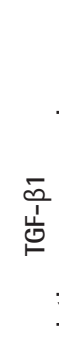

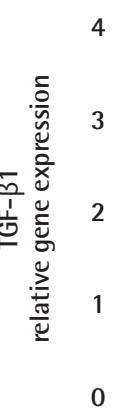

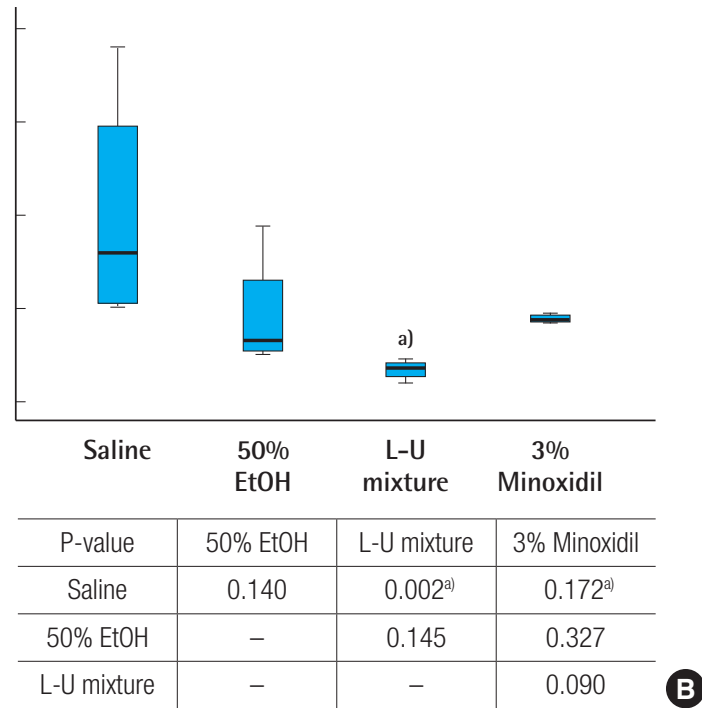

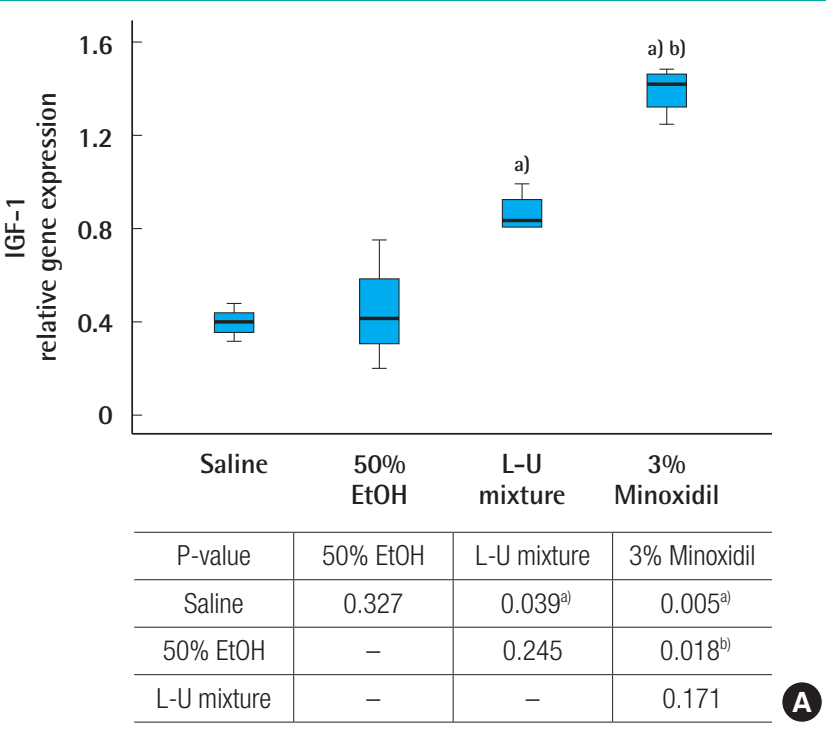

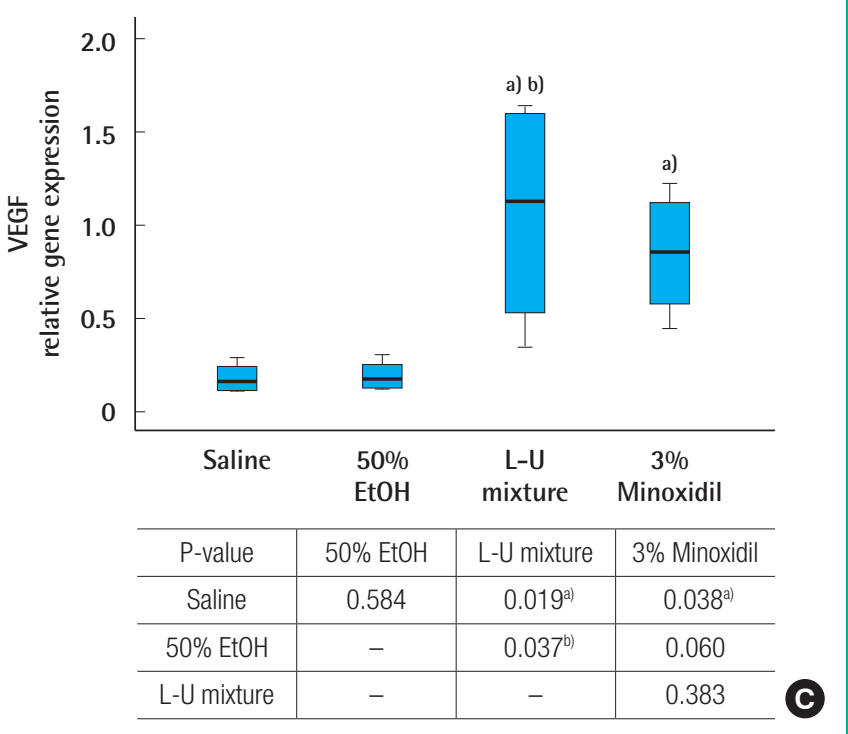

than medical treatment, surgical treatments might have some obstacles, such as the time or the cost of the treatment. On the other hand, medical treatments can save not only the time used in hair loss treatment, but could also provide convenience to the patients, thus enabling most patients to treat their hair loss with hair growth solution [12].

Studies have reported hair growth promotion effects of natural materials, including plants [13-15]. In addition, the use of algae in medical applications, is increasing. Marine organisms are known to be rich sources of biologically active substances [16]. Study of Gloiopeltis furcata has demonstrated a therapeutic effect on hepatoma cancer; treatment with $U$. pinnatifida extract reduced edema and immune reaction [17-19]. The study of fucoidan from brown algae has shown it is as effective as dexamethasone in treatment of atopic dermatitis symptoms in mice
[20]. In a hair loss prevention study, I. sinicola extract induced significant inhibition of the activity of $5 \alpha$-reductase [8]. G. elliptica extract has potential in the treatment of alopecia via the proliferation of dermal papilla, $5 \alpha$-reductase inhibition, increase of prostaglandin E2 production, decrease of lipopolysaccharidestimulated pro-inflammatory cytokines, and inhibitory activity against Pityrosporum ovale (=Malassezia furfur) [9]. In this study, the L-U mixture was analyzed by GC-MS (Table 1). The $\mathrm{CH} 2 \mathrm{Cl} 2$ fraction had 18 components and major components were nonacosan-10-ol and $\beta$-sitosterol. A third component, (-)-loliolide, was determined in marine algae including red, brown and green algae and also including U. pinnatifida [21]. (-)-Loliolide has been reported to protect cells against $\mathrm{H}_{2} \mathrm{O}_{2}$ induced cell damage or apoptosis [22].

We performed histological and molecular biological analyses 
Table 1. Chemical component analyzed $\mathrm{CH}_{2} \mathrm{Cl}_{2}$-fraction from the $\mathrm{L}-\mathrm{U}$ mixture (the extract of Laminaria japonica and Undaria pinnatifida) by gas chromatography with mass spectrometry

\begin{tabular}{|c|c|c|c|c|}
\hline RT & Area $(\%)$ & CAS no. & MW & Library \\
\hline 17.82 & 1.27 & $5989-02-6$ & 196 & (-)-Loliolide \\
\hline 22.81 & 0.59 & $486-21-5$ & 222 & Isofraxidin \\
\hline 23.36 & 0.61 & $7459-33-8$ & 298 & 9, 12-0ctadecadienoyl chloride \\
\hline 24.6 & 0.23 & $4752-56-1$ & 288 & 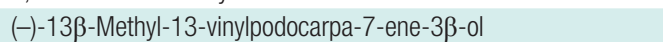 \\
\hline 24.99 & 0.22 & $5949-49-5$ & 288 & (6beta)-6-hydroxyestr-4-ene-3,17-dione \\
\hline 25.59 & 0.28 & $511-15-9$ & 286 & Totarol \\
\hline 25.76 & 0.29 & $56053-09-9$ & 304 & Pregnan-18-0l \\
\hline 27.13 & 0.23 & $124183-18-2$ & 360 & 7-0xo-12-methoxy-6,11,14-trihydroxy-abieta-5,8,11,13-tetraene \\
\hline 28.16 & 0.17 & $119971-00-5$ & 301 & 2,6-Dimethyl- $N$-(2-methyl- $\alpha$-phenylbenzyl) aniline \\
\hline 28.62 & 0.19 & $5908-87-2$ & 368 & Ethyl ester of docosanoic acid \\
\hline 29.67 & 0.24 & $3443-84-3$ & 356 & 2-0leoylglycerol \\
\hline 29.92 & 0.24 & $621-61-4$ & 358 & Octadecanoic acid \\
\hline 31.7 & 0.24 & $630-03-5$ & 408 & Nonacosane \\
\hline 32.02 & 0.14 & $73275-02-2$ & 344 & 10-Methyl-1,8-diphenyl anthracene \\
\hline 33.65 & 2.28 & $504-55-2$ & 424 & Nonacosan-10-ol \\
\hline 35.8 & 0.27 & $297-35-8$ & 420 & Cyclotriacontane \\
\hline 35.98 & 0.22 & 18835-33-1 & 364 & 1-Hexacosene \\
\hline 36.33 & 1.69 & $83-47-6$ & 414 & $\beta$-Sitosterol \\
\hline
\end{tabular}

for detection of hair regrowth effects. TGF- $\beta$ regulates the growth, apoptosis, and specialization of cells. TGF- $\beta$ includes TGF- $\beta 1$, TGF- $\beta 2$, and TGF- $\beta 3$, all of which suppress keratinocyte proliferation and take part in extracellular matrix protein degradation by fibroblasts. A recent study reported that TGF- $\beta 1$ plays a significant role accelerating hair loss. TGF- $\beta 1$ hinders growth of anagen phase hair, causing hair to enter catagen phase, thereby inducing alopecia [7]. Synthesis of TGF- $\beta 2$ was stimulated by dihydrotestosterone in dermal papilla cells [23]. In our study, the expression of TGF- $\beta 1$ for the topical treatment of the L-U mixture was less than 3\% minoxidil, which means the L-U mixture has potential for hair loss prevention.

Growth factors such as IGF-1, EGF, and FGF promote hair growth and prevent involution of hair cells, playing an important role in hair follicle cycling and development, as well as specifying cell proliferation [24]. Our results showed increased expression of IGF-1 in L-U mixture treated mice, and increased expression of VEGF in 3\% minoxidil treated mice. The RT-PCR data showed the same pattern of increase or decrease with both L-U mixture and minoxidil. Mice treated with the L-U mixture showed an increase of hair regrowth, follicle size, and number. Results from H\&E staining provided evidence to support promotion of hair growth by treatment with the L-U mixture and $3 \%$ minoxidil. The L-U mixture had a hair growth effect similar to that of minoxidil. Based on these results, we suggest that the L-U mixture may promote hair growth and prevent involution of hair cells.

\section{REFERENCES}

1. Ambrosio GB. Minoxidil in resistant hypertension. Lancet 1977;2:1087.

2. Paus R. Therapeutic strategies for treating hair loss. Drug Discov Today Ther Strat 2006;3:101-10.

3. Price VH, Menefee E. Quantitative estimation of hair growth. I. androgenetic alopecia in women: effect of minoxidil. J Invest Dermatol 1990;95:683-7.

4. Cotsarelis G, Millar SE. Towards a molecular understanding of hair loss and its treatment. Trends Mol Med 2001;7:293301.

5. Danilenko DM, Ring BD, Pierce GF. Growth factors and cytokines in hair follicle development and cycling: recent insights from animal models and the potentials for clinical therapy. Mol Med Today 1996;2:460-7.

6. Philpott MP, Sanders DA, Kealey T. Effects of insulin and insulin-like growth factors on cultured human hair follicles: IGF-I at physiologic concentrations is an important regulator of hair follicle growth in vitro. J Invest Dermatol 1994; 102:857-61.

7. McElwee KJ, Huth A, Kissling S, et al. Macrophage-stimulating protein promotes hair growth ex vivo and induces anagen from telogen stage hair follicles in vivo. J Invest Dermatol 2004;123:34-40.

8. Kang JI, Kim EJ, Kim MK, et al. The promoting effect of Ishige sinicola on hair growth. Mar Drugs 2013;11:1783-99. 
9. Kang JI, Kim SC, Han SC, et al. Hair-Loss Preventing effect of Grateloupia elliptica. Biomol Ther (Seoul) 2012;20:11824.

10. Bak SS, Ahn BN, Kim JA, et al. Ecklonia cava promotes hair growth. Clin Exp Dermatol 2013;38:904-10.

11. Cho JY, Kang JY, Khan MN, et al. Anti-inflammatory activities of Undaria pinnatifida and Laminaria japonica (Phaeophyta). J Fish Sci Technol 2007;10:127-32.

12. Ha WH, Park DH. Effect of seaweed extract on hair growth promotion in experimental study of C57BL/6 mice. Arch Craniofac Surg 2013;14:1-10.

13. Hirata N, Tokunaga M, Naruto S, et al. Testosterone 5alphareductase inhibitory active constituents of Piper nigrum leaf. Biol Pharm Bull 2007;30:2402-5.

14. Junlatat J, Sripanidkulchai B. Hair growth-promoting effect of Carthamus tinctorius floret extract. Phytother Res 2014; 28:1030-6.

15. Kumar N, Rungseevijitprapa W, Narkkhong NA, et al. 5alpha-reductase inhibition and hair growth promotion of some Thai plants traditionally used for hair treatment. J Ethnopharmacol 2012;139:765-71.

16. Jung HA, Oh SH, Choi JS. Molecular docking studies of phlorotannins from Eisenia bicyclis with BACE1 inhibitory activity. Bioorg Med Chem Lett 2010;20:3211-5.

17. Bae SJ, Choi YH. Methanol extract of the seaweed Gloio- peltis furcata induces G2/M arrest and inhibits cyclooxygenase-2 activity in human hepatocarcinoma HepG2 cells. Phytother Res 2007;21:52-7.

18. Khan MN, Yoon SJ, Choi JS, et al. Anti-edema effects of brown seaweed (Undaria pinnatifida) extract on phorbol 12-myristate 13-acetate-induced mouse ear inflammation. Am J Chin Med 2009;37:373-81.

19. Leonard SG, Sweeney T, Bahar B, et al. Effect of maternal seaweed extract supplementation on suckling piglet growth, humoral immunity, selected microflora, and immune response after an ex vivo lipopolysaccharide challenge. J Anim Sci 2012;90:505-14.

20. Yang JH. Topical application of fucoidan improves atopic dermatitis symptoms in NC/Nga mice. Phytother Res 2012;26:1898-903.

21. Kimura J, Maki N. New loliolide derivatives from the brown alga Undaria pinnatifida. J Nat Prod 2002;65:57-8.

22. Yang X, Kang MC, Lee KW, et al. Antioxidant activity and cell protective effect of loliolide isolated from Sargassum ringgoldianum subsp. coreanum. Algae 2011;26:201-8.

23. Hibino T, Nishiyama T. Role of TGF-beta2 in the human hair cycle. J Dermatol Sci 2004;35:9-18.

24. Zhang D, Lijuan G, Jingjie L, et al. Cow placenta extract promotes murine hair growth through enhancing the insulin like growth factor-1. Indian J Dermatol 2011;56:14-8. 